Article

\title{
Safeguarding, Chaplaincy and English Professional Football
}

\author{
Mark Oliver and Andrew Parker * \\ School of Sport and Exercise, University of Gloucestershire, Gloucester GL2 9HW, UK; \\ mark@friendlydevelopment.co.uk \\ * Correspondence: andrewparkerconsultingltd@gmail.com
}

Received: 3 July 2019; Accepted: 11 September 2019; Published: 22 September 2019

\begin{abstract}
In recent years, English professional football has been rocked by allegations of historical sexual abuse and safeguarding concerns around young players. This paper examines the potential contribution that sports chaplains can make to the specific welfare needs of elite youth footballers within the wider context of safeguarding practices and protocols. Comprising a small-scale, sociological study involving welfare personnel at English Premier League and English Football League Championship clubs, the paper identifies the scope and potential of sports chaplaincy in relation to the practical outworking of safeguarding policy. Findings reveal that elite youth footballers face a number of pressures specific to the highly competitive environment in which they work and that various safeguarding issues routinely arise amidst these pressures. The paper concludes by suggesting that sports chaplains are ideally placed to provide safeguarding and wider welfare support to young players as a consequence of their independence from team management structures and their prioritization of holistic care above performance-related issues.
\end{abstract}

Keywords: safeguarding; elite youth sport; English professional football; qualitative research

\section{Introduction}

Association (professional) football in the UK has been subject to an unprecedented number of allegations of abuse in recent years, the majority of which date back over several decades. These historical cases have impacted a significant number of individuals and organisations from grassroots to elite level with the integrity of coaches and officials coming into question around safeguarding issues (see, Conn 2018; Morris 2019; Taylor 2018; Wallace 2019). As a consequence, governing bodies of sport in the UK have been stimulated to implement robust safeguarding policies and procedures in order to provide safer, nurturing environments in which young people can thrive (see, for example, The Football Association 2015, 2017). ${ }^{1}$

Sports chaplaincy has developed markedly during the same period and is represented in a large number of professional football clubs in the UK providing holistic pastoral and spiritual care both for athletes and wider employee groups. A small body of research has emerged detailing the working lives of chaplains within this context yet little has been written about how and to what extent sports chaplains might specifically contribute to the safeguarding and wider welfare support of elite youth footballers. This paper aims to address this shortfall by exploring some of the pressures and associated safeguarding issues that exist within this particular context and by investigating the extent to which chaplains may have the opportunity to make a meaningful contribution in this area.

1 For further discussion on the role of chaplaincy provision within the broader context of athlete welfare and wellbeing see Hemmings et al. (2019a). 
The paper begins by discussing recent welfare reforms in UK professional sport especially those surrounding safeguarding. Following this, we explore the roles and responsibilities of chaplains in professional football and some of the specific pressures faced by elite youth players. Drawing upon the findings of a small-scale, sociological study into safeguarding provision at six English professional football clubs, the paper reveals that elite youth footballers often face a range of performance-related pressures from coaches, parents and peers which, if not dealt with appropriately, may lead to wider welfare concerns. Findings also reveal that safeguarding co-ordinators were unanimous in their recommendation of club chaplains and their unique position as trusted figures who can provide pastoral support independent of those in decision-making positions. The paper concludes by suggesting that sports chaplains can contribute meaningfully to both the safeguarding and wider welfare needs of elite youth footballers.

\section{Safeguarding and UK Sport}

In the UK at least, the prominence of safeguarding has increased markedly both in sport and wider social contexts during the 21 st century. ${ }^{2}$ Awareness of abuse has been raised via media coverage of allegations involving high-profile individuals and institutions, whilst child protection training, policies and praxis such as criminal record checks have also placed safeguarding in the public consciousness. ${ }^{3}$

In her review of duty of care and safeguarding procedures in sport, ex-Paralympian (Baroness) Grey-Thompson (2017) argues that success in sporting contexts is often dependent upon prioritizing participant safety, wellbeing and welfare. This reflects Sport England (2016) current strategic aim to see wider, holistic personal development outcomes prioritised over and above more traditional objectives such as increased sporting participation and elite success. However, this has not always been the case and prior to the 1980s sport was often viewed as a somewhat disparate and isolated entity, lacking accountability to wider social structures (Brackenridge and Rhind 2014). The Child Protection in Sport Strategic Plan developed between the UK National Society for the Protection of Cruelty to Children (NSPCC) and Sport England, states that the focus for safeguarding in sport should be on elite athletes as they are amongst the most likely to face discrimination, exclusion and abuse due to the unique pressures associated with such levels of performance (Sport Safeguarding Partnership 2016).

In terms of the propensity of sporting environments to breach safeguarding norms, the culture within English professional football is a case in point. In recent years, the reputation of football has been significantly impacted by allegations of historical sexual abuse attributed to an institutional culture of power and control. ${ }^{4}$ As a consequence, football's governing bodies have sought to develop and implement robust safeguarding policies and procedures in a co-ordinated attempt to prevent the recurrence of such events, a strategy which has included significant investment to embed specialist safeguarding provision across all levels of the sport and to promote a collaborative approach to wider welfare concern in order to cater for the holistic development of players. This work has stimulated improved safeguarding policies and training and has included the launch of the Football Association's (FA) Child Protection strategy in 2000 (Brackenridge et al. 2004, 2005).

Concurrently, the FA became the first UK national governing body of sport to commission a major investigation into child protection which was tasked with evaluating the impact of these policy measures on the culture of the professional game (see Pitchford et al. 2004). Featuring over 300 amateur football clubs, one of the key findings of this work revealed patterns of failure around the safeguarding of youth participants (Pitchford et al. 2004; Brackenridge et al. 2005) which subsequent policies have

2 In the UK, the term 'safeguarding' refers to the protection of the health, wellbeing and human rights of children/young people and adults at risk, enabling them to live safely and free from abuse and/or neglect. For more on the importance of safeguarding within the context of broader sport for development agendas see Giulianotti et al. (2019).

3 This section of the paper draws upon some of our previously published work (see Hemmings et al. 2019b).

4 An Independent Review into Child Sex Abuse Allegations in Football is currently being led by Clive Sheldon QC. The Review into what the Football Association and Clubs knew and did about allegations of child sexual abuse between 1970 and 2005 has run alongside ongoing criminal investigations (see BBC 2018; Roan 2019). 
attempted to address (see Mountjoy et al. 2015; Sport Safeguarding Partnership 2016; Grey-Thompson 2017; Ong et al. 2018).

Other safeguarding issues reported in the study included the aggressive touchline behaviours of parents and allegations of underage alcohol consumption. Although this research focused on grassroots football, resulting data suggested that abusive behaviours increased proportionately with ability level (Brackenridge et al. 2004; Brackenridge and Rhind 2014), a pattern validated by more recent research findings (International Centre of Ethics in Sport 2016; Grey-Thompson 2017; Ong et al. 2018).

Of course, it is well-established that elite youth athletes are more likely to experience overtraining, performance-related stress and excessive mental and emotional pressure (Mountjoy et al. 2015; Manley et al. 2016; Parker 2016; Parker and Manley 2016, 2017). Likewise, it is acknowledged that a variety of safeguarding issues can arise in elite youth sport as a consequence of the dependency dynamics in play and the intense nature of coach-athlete relations (Brackenridge et al. 2005; International Centre of Ethics in Sport 2016; Grey-Thompson 2017). These issues can be perpetuated by the prioritization of performance over pastoral care (Ong et al. 2018), an area in which some coaches appear to lack suitable skills and knowledge (Grey-Thompson 2017). According to Mountjoy et al. (2015), recent studies reveal that the coach is not always the perpetrator of abuse, particularly in the case of bullying and 'hazing', where peers are most likely to act as instigators (see Kavanagh 2014, Brackenridge and Rhind 2014). Informal 'banter' between participants is commonplace in elite sport (Grey-Thompson 2017) and may often mask psychological and emotional vulnerabilities (Ong et al. 2018), with players possessing a wide range of coping strategies. The harsh realities of such interaction have long been recognised within the context of youth football (Pitchford et al. 2004; Brackenridge et al. 2004); examples including the verbal chastisement and the physical 'punishment' of players by coaches (see Parker 1995). For this reason, Grey-Thompson (2017) urges coaches to identify instances where 'banter' leads to bullying and to eradicate the damaging elements of such behaviours. In turn, she acknowledges the imbalance of power between coach and athlete, arguing that these dynamics can often be viewed as 'the norm' in elite sport; a rite of passage that participants are expected to endure given their lack of influence in terms of culture change (see Parker 2001, 2006).

Research and policy around safeguarding have led to a number of practical recommendations for creating safer sporting environments. It is suggested, for example, that football (and sport more broadly) should change its overall approach by adopting a child-centred player development model suitable for the unique culture in which young people are based (Ong et al. 2018; Pitchford et al. 2004; International Centre of Ethics in Sport 2016). Moreover, elite players (of all ages) should be supported during transitions into and out of sport, with player welfare being embedded in robust induction and de-selection processes (Grey-Thompson 2017). There is evidence in English professional football of youth academy staff being encouraged to place greater emphasis on the establishment of trust and rapport with players in order to better understand their behaviours and facilitate meaningful conversations (Ong et al. 2018). For example, recent developments at Manchester City Football Club have witnessed collaborations between medical, safeguarding, psychology and sports science teams in order to enhance player welfare (Ong et al. 2018). In turn, Grey-Thompson (2017) highlights the importance of referring athletes to 'independent and confidential support services' as players often fear jeopardising their careers if they raise welfare concerns with coaching staff. Such holistic practices clearly present opportunities for helping professionals—including sports chaplains—-to bring together their individual and collective skills and expertise in relation to wider welfare support (see Hemmings et al. 2019b). ${ }^{5}$

5 For more critical discussion of the implications of the increased prevalence of safeguarding protocols on elite sport see Baker et al. (2017) and Barker-Ruchti (2019). 


\section{Chaplaincy and UK Sport}

Sports chaplaincy in the UK mirrors many of the roles and responsibilities of generic chaplaincy, i.e., pastoral/spiritual care, crisis support and personal discipleship (Parker et al. 2016). These duties must be underpinned by the chaplain's ability to apply them to the specific context in which they find themselves (Slater 2015; Swift et al. 2015; Caperon et al. 2018). It would be fair to say that English professional football has featured large in the development of UK sports chaplaincy acting as a catalyst for the emergence of such provision across elite sport and serving as a training ground for numerous practitioners (see Heskins and Baker 2006). As is the case for many chaplains operating in elite football, those featured in the present study all occupied positions of marginality within their host institutions (see, for example, Roe and Parker 2016), a culturally hostile environment renowned for its occupational instability and hyper-masculine workplace practices (Roderick 2006; Parker 2001, 2006). Whilst at first glance marginality might be viewed as something of a disadvantage, Pattison (2015) has argued that as an accepted part of chaplaincy practice, such role ambiguity may in fact bring with it a whole series of benefits in relation to organisational access and influence.

Chaplaincy provision has increased significantly in English professional football in more recent years. For example, the majority of English Premier League clubs now have a sports chaplain working as part of their broader holistic support networks. In this role, chaplains offer practical, spiritual and pastoral support, as well as providing assistance with wider lifestyle issues (Gamble et al. 2013; Nesti and Sulley 2015). At times, players and staff may be reticent to engage with such support on account of the mistaken perception that the chaplain is there to proselytise their faith and research suggests that club managers may be influential in this respect (Roe and Parker 2016). In their study of the relationship between sports chaplains and sport psychologists in the English Premier League, Gamble et al. (2013) found that chaplains felt that their role may be either empowered or disempowered depending on the attitude of a team manager towards them. Nesti and Sulley (2015) emphasise the significance of these facets of organisational culture, arguing that they often provide an unspoken set of rules that represent the club's collective morality, allowing or prohibiting certain types of behavior. However, Nesti and Sulley (2015) go on to argue that the chaplain's ability to function as an effective, yet distinct, part of a club's support network is fundamentally reflective of the depth of relationships that they build with players and staff.

In elite sports settings, the work of the chaplain often enhances broader welfare provision identifying such opportunities through cross-departmental dialogue (Hemmings and Chawner 2019) and by responding flexibly to the needs of those around them. It is argued that such practices can contribute to improved athlete performance but it is the distinct spiritual nature of the chaplain's work which enables them to place value on each individual, regardless of their perceived worth to club officials, coaches or to the team itself (Gamble et al. 2013). Given the degree of uncertainty surrounding the personal and professional lives of elite youth footballers and the social and psychological challenges that they face (Professional Footballers' Association 2017), Baker (2006) argues that sports chaplains should be mindful of the specific needs of young players. One of the ways in which this often plays out within the context of English professional football is via the neutrality and independence of the chaplain's position in relation to club hierarchies and decision making processes (Weir 2016). Unlike other support services, chaplains are not typically employed by the clubs that they serve and do not therefore report directly to management on matters of welfare or performance (Roe and Parker 2016). Professional footballers can be reluctant to speak to those with decision-making responsibilities (i.e., club management and coaching staff) about personal issues due to the impact that this may have on team selection and/or career progression (Nesti and Sulley 2015). A central strength of chaplaincy is the prioritization of player personal need over and above that of team performance (Comfort 2006; Baker 2006). Although arguments prevail around the negative implications of this independent if marginalized (and somewhat isolated) position (Knight 2006; Comfort 2006), it is the central contention of this paper that such a role is fundamental to the chaplain's capacity to contribute to the safeguarding of elite youth players. 


\section{Methodology and Method}

Professional football academies facilitate a comprehensive programme of competition, training, education and support for boys and young men in structured age-groups between nine and 23 years of age (The English Football League 2018). Depending upon the nature of the academy in question (four category levels of academy exist based on the standard of resources and facilities on offer, i.e., staff/coaching, sports science and education), players progress through part-time, full-time or hybrid models of training and education negotiated between club, parents and school (The Premier League 2018). At 16, those young players who are to be retained by their host club are offered a formal 'scholarship' which comprises a full-time footballing contract accompanied by part-time academic study, typically amounting to the completion of an advanced apprenticeship in sporting excellence, alongside their holistic development as athletes. This includes time allocated to focus on life skills including workshops delivered by club staff and external agencies who specialise in a variety of topics relating to the pressures often faced by young players such as gambling, substance misuse, social media and personal relationships (Professional Footballers' Association 2017).

The research reported here was carried out between November 2017 and March 2018 and the primary method of data collection was semi-structured interviews. The aim of the research was to explore whether and to what extent sports chaplains could make a meaningful contribution towards safeguarding in professional football. Interviews took place with those responsible for wider welfare support in football clubs which hosted a sports chaplain ${ }^{6}$ and were carried out within six clubs; three from the English Premier League and three from the English Football League Championship, all of which were located in urban conurbations across the north and south of the UK. The Premier League and Championship clubs were represented by their Heads of Safeguarding and Heads of Education and Welfare respectively, in accordance with each league's safeguarding policies. In order to ensure that an appropriate data set was obtained, purposive sampling was used in relation to participant selection (Bryman 2015).

Prior to the onset of the research, ethical approval was granted by the University of Gloucestershire. All respondents were contacted directly via email in the first instance and each was issued with an information sheet and consent form regarding the collation of data prior to interviews taking place. Interviews lasted between 30 and $40 \mathrm{~min}$ and were audio recorded and transcribed in full. Four were held in-person at the host clubs of respondents and two were conducted via Skype. Interview questions were derived from the background academic and policy literature in the area and framed in line with the specific focus of the research itself. Respondents were asked to reflect on their roles and responsibilities relating to wider welfare support including how they helped players deal with the specific pressures that may arise in elite youth football. They were also invited to discuss the types of safeguarding issues that may emerge within this context. Respondents were then asked to share their understanding of the sports chaplains' role in their respective clubs and to comment on whether they thought there was potential for chaplains to contribute (or contribute further) towards some of the pertinent safeguarding and wider welfare issues in play. Finally, respondents were invited to share any further relevant information. The questioning style during interviews was open-ended and, where necessary, further probing took place to clarify responses. Discussions focused on a range of issues surrounding the holistic wellbeing and/or performance of elite youth players. In line with conventional practice concerning processes of respondent validation, all participants were offered the opportunity to review their interview transcripts for accuracy (Bryman 2015). In the interests of anonymity, pseudonyms have been used throughout the present discussion.

A grounded theory approach to data analysis was deployed in line with Strauss and Corbin (1998). Grounded theory allows for the systematic analysis of data through a process of open, axial and selective coding and the formation of a conceptual framework that facilitates the presentation of 
participant experiences from their own perspective (see Charmaz 2000, 2014). To this end, data were analysed in four stages. Firstly, transcripts were read in full to gain a comprehensive overview of the data. Secondly, each transcript was individually coded and indexed whereby a capturing of the different aspects of participant experience took place. Thirdly, these experiences were then categorised into a number of over-arching topics. The final stage of analysis involved the formal organisation of these topics into generic themes two of which provide the focus for the remainder of our discussion. The first highlights the kind of safeguarding issues that respondents found themselves dealing with while the second explores how and to what extent chaplains may contribute to safeguarding and wider welfare support within youth football. Prior to our detailed consideration of these themes, we present a snap-shot of the occupational profiles of each of our respondents and their histories in the professional game.

\section{Edith Ford-Head of Safeguarding, Sunnyside Rovers (English Premier League).}

Edith Ford has worked at Sunnyside Rovers for more than 20 years, fulfilling various roles including Women and Girls' Football Development Officer. In 2004 she became the club's Head of Education and Welfare, working predominantly with their youth academy (eilte) players. In 2016, she was appointed to the role of Head of Safeguarding operating across all areas of the club.

Andy Sharpe, Head of Education and Welfare, Dipton Town FC Academy (English Football Championship).

Andy Sharpe has been Dipton Town's Head of Education and Welfare since 2014, a role that sits within the club's academy structure. Prior to this, he was a part-time educational tutor in the academy, having begun his career as a physical education teacher in further (post-16) education.

Felicity Archer, Head of Safeguarding, Highfield FC (English Premier League).

Felicity Archer has operated as Head of Safeguarding at Highfield FC since 2012, having previously fulfilled the role of Training Manager for the club's education provider. She began life at Highfield as a match-day steward which led to a coordination and training role with stewards at other local clubs.

Jon Clark, Head of Welfare, Tanfield FC (English Football Championship).

Jon Clark has been the Head of Welfare at Tanfield FC since 2018. Prior to this, he was involved in the club's academy as an educational tutor having begun his career as a college lecturer in sports science. A trained sports therapist, he also spent 12 years in a part-time role in the medical department of another local club.

\section{Neil Cordingley, Head of Education and Welfare, Hobson FC (English Football Championship).}

Neil Cordingley has been Head of Education and Welfare at Hobson FC since 2016, having previously been the Education Officer for the club's Community Department for five years. As a youngster, he played for Hobson's Centre of Excellence.

\section{Owen White, Head of Safeguarding, Sherburn United FC (English Premier League).}

Owen White has been the Head of Safeguarding at Sherburn FC since 2016. He previously served in the police force and has 20 years' experience in safeguarding. He has also been a part-time football coach at another Premier League academy.

\section{Safeguarding and Elite Youth Football}

As we have seen, the profile of safeguarding in English professional football has risen exponentially in recent years as a consequence of the pioneering work of Brackenridge et al. $(2004,2005)$. This has influenced a culture-shift within elite youth sport (National Society for the Prevention of Cruelty to Children) a development that Edith Ford of Sunnyside Rovers bore witness to: 
Within football we've had the disclosures of the ... historical sexual abuse, and that's, probably when I came into post. Looking back to 2004, society in general, people didn't talk about it. Prior to that there was an acceptance that these things were happening but nobody ever spoke about it. I guess what's changed now is people are not afraid to come [to a safeguarding officer] and they expect something to happen; it's that expectation that they come and there's a disclosure and that something will happen.

It is worth noting that none of the respondents in this study referred to allegations of sexual abuse within their own clubs and only broached this matter in order to emphasize the increasing profile and scope of safeguarding within the professional game. It is also worth noting that recent research into safeguarding has shifted from being focused solely on sexual abuse to cover a wider range of contextual issues (see Brackenridge and Rhind 2014). The current Child Protection in Sport (CPSU) Strategic Plan, developed in partnership between the NSPCC and Sport England, states that the focus for safeguarding in sport should be on elite athletes as they are amongst the most likely to face discrimination, exclusion and abuse due to the unique pressures associated with performance level sport (Sport Safeguarding Partnership 2016). Although some generic safeguarding issues such as underage drinking and social media usage emerged during interview discussions, the majority of the risks that arose during these conversations related to the specific environment in which elite youth footballers operate. Owen White of Sherburn United provided an example of the protective 'bubble' that elite footballers can become accustomed to and the subsequent welfare risks that may arise:

Yes, they [the young players] may be very wealthy but they have the same problems as you and I do and they potentially are more vulnerable than you and I because ... they've been cosseted from lots of life's ups and downs. Yet they're going to face them at different stages of their life, and if they've never faced a crisis in a relationship and the first crisis they face, they happen to be in the peak of their career, who do they turn to?

Another wider safeguarding risk that was highlighted by respondents was how youth footballers occupied the considerable amount of down-time that their lifestyles afford. Jon Clark of Tanfield FC Academy shared his specific concerns over the gambling habits of players:

And I do worry constantly about the amount of time they have and if they're getting involved in things they shouldn't do because it can lead them into problems of addiction and things like that.... It's [gambling] something that gives them an adrenaline kick like they get on a match day.... I saw an Under-12 boy playing a football game, and one of the things he's got to do before he gets on the game is have a roulette spin to get the colours for his team. And I'm just thinking, what you're doing there quite cleverly, is getting the boys to enjoy the roulette experience, so you're drawing them in at $10,11,12 \ldots$

The most dominant safeguarding issue to emerge in interview was that of 'bullying', with four of the six respondents providing recent examples of both verbal and physical bullying that had taken place within their club. This was another issue around which Jon Clark (Tanfield FC) had concerns:

And there's the kind of welfare issues that go alongside ... So, for example, we'll have accusations of bullying, from boys to boy, or from parents about another boy, accusations that maybe ... staff could do a little bit more in supporting their boy.

As we have seen, allegations of bullying are not uncommon within the context of elite youth football amidst what has been identified as a hyper-masculine culture of power and control (Parker 1995; Pitchford et al. 2004; Brackenridge et al. 2004). Andy Sharpe of Dipton Town suggested that behaviours which could be interpreted as peer-group bullying were occasionally evident within his club:

Bullying's a strong word. But some of the boys saying some unkind things in training or so on ... they're typical 'bread and butter' issues that come up from time to time for schoolboys. 
Whether bullying is too strong a word to describe such relational dynamics is open to debate and, as we have seen, similar issues have been called into question within recent literature and policy surrounding the wider welfare of elite athletes (see Mountjoy et al. 2015; International Centre of Ethics in Sport 2016; Grey-Thompson 2017; Ong et al. 2018). In order to provide a safe and supportive environment in which players can thrive, Jon Clark went on to argue that a clear distinction needed to be made between 'banter' and bullying:

And I also think that ... allegations made by parents about their sons being bullied have increased significantly and I think there's a lot of parental education needed in terms of what is an appropriate form of 'banter' and what's not.

Grey-Thompson (2017) corroborates the need to provide clarity in this area, suggesting that whilst banter is usually light-hearted, occasional and reciprocal, it can lead to bullying which is one-sided, intentional and persistent, unless clear boundaries are established and maintained (see Parker 2001, 2006). The potential consequences of failing to form this distinction were highlighted by Edith Ford, who explained that one player's experience of alleged 'targeted abuse' from a coach at Sunnyside Rovers led to them contemplating suicide, resulting in an internal investigation.

In order to combat these issues, clubs now provide educational workshops for their academy players around anti-bullying7 ${ }^{7}$, as Andy Sharpe of Dipton Town FC explained:

I'll do anti-bullying sessions so again, from time to time you'll get it from team mates, or a boy who's not playing well at the moment, we'll try and nip it in the bud ... educate them about ... the importance of all getting on; because that's going to make them a better team and play better individually.

These shifts in the profiling of safeguarding and the education of youth players should be seen as progressive. Yet, the motive to provide such training, often appeared to be based on optimal team performance rather than the holistic development of the athletes in question. It could be argued that the offer of additional resources in the shape of the pastorally-focused club chaplain could help contribute towards the wider welfare support of elite youth football players and the following discussion explores perceptions of club chaplaincy and the potential to utilize its services in this way.

\section{Safeguarding, Chaplaincy and Welfare Support}

Without exception respondents spoke positively about the role of the chaplain within their clubs in terms of contributing to the wider welfare support network of elite youth footballers. Central to their observations was the importance of the chaplain becoming embedded within the academy or wider club environment. This was most clearly articulated by Andy Sharpe of Dipton Town FC:

He [the chaplain] comes in on a Thursday and he sort of makes his way around the club really and he's a familiar face. [He's] part of that support network; part of the Dipton Town family. All of our academy players are aware of the club chaplain. He also does an introductory talk as part of the 'Lifestyle Management' [curricular] programme with our Under 18s and our [Under] 23s.

Neil Cordingley also provided insight into how the chaplain at Hobson FC had developed relationships with the staff and players thereby reflecting the incarnational approach typically adopted by sports chaplains in the UK (see Mason 2006; Boyers 2016):

Yeah, with being here for sort of seven years, in or around the club, obviously I've seen Bob [chaplain] quite a lot when he comes in on a Thursday ... And he comes around and has a

7 Respondents also provided details of workshops on wider safeguarding issues such as consensual relationships, addiction and social media use. 
chat, just checks if everyone's OK. But, $\mathrm{y}^{\prime}$ know, there's genuine support there from him, that if anyone needs to speak to [him] ... they can do.

Two respondents from Championship clubs stated that having a club chaplain was recognized as 'good practice' by League Football Education (the governing body of academy curricular) and by Ofsted (the UK government accountability body for curricular delivery). It could be argued that this is due to the chaplain focusing on the wider welfare of players through the provision of consistent pastoral support as opposed to performance issues (Roe and Parker 2016). In turn respondents provided examples of their club chaplains conducting religious ceremonies such as carol services, weddings and funerals as well as the pastoral care services that surrounded these significant life events.

That said, chaplaincy had clearly not always engendered such positive responses. For example, Edith Ford spoke candidly about how at one time, Sunnyside Rovers staff used to 'run for cover' when the club chaplain appeared. In their qualitative study of one English Premier League Academy, Roe and Parker (2016) argue that some players may be reluctant to utilise the chaplain due to their fears of their evangelistic agenda. Edith Ford went on to explain how she had come to view her club chaplain as faith-based, but not faith-biased. Likewise, Owen White shared his initial reservations about the chaplain at Sherburn United and how his thoughts had changed over time:

Once I understood what Charlie's motivation was and that it wasn't to fill his congregation, I very quickly switched onto the fact that this was a free resource that I could tap into. His role as I see it is very much to be visible, to be there, to engage with people and to offer them, if they feel they need it, someone who they can talk to.

Owen's statement about chaplaincy as a 'free resource' paints a typical picture of how UK sports chaplains operate. None of those featured in this research were paid employees of their respective football clubs; rather, they acted as volunteers or within their role as local clergy (Weir 2016; Boyers 2016). A dominant trend to emerge from interview discussion was the significance of the independent nature of the chaplain and how this might positively impact working practice. Edith Ford provided a comprehensive analysis of this:

If I'm unsure about something, I can chat [it] through with him [the chaplain] and he'll give me a really honest opinion and I know that that's not going anywhere and it's not coloured by any other football opinions ... Because within a football club, everything is ... it's not real. Everything is twisted and skewed because football is everything; football has got its own rules; they do what they want. Y'know, but actually there's rules and regulations out there. So sometimes ... it's good to sort of step back and to speak to someone who's not involved with that ... So, he is very, very neutral. And ... for a lot of ... things he doesn't have that emotional involvement. He's perhaps not as close [to the club]—sometimes I get a bit close-he's better placed.

As well as providing a sense of objectivity and impartiality, it could be argued that a further benefit of chaplains not being directly employed by clubs is the added layer of independence from management and coaching staff that this provides (Gamble et al. 2013; Roe and Parker 2016), something which Jon Clark reflected upon:

I think sometimes the boys would be frightened to say [to a member of the management or coaching staff]: 'This has happened at the weekend, so I've been involved in this situation' as an example. 'Cos, if the club find out, they won't be happy. And they don't see Roland [the chaplain] — because he doesn't wear the tracksuit—as a direct employee of the club. They just see him as a nice guy to talk to.

Such a scenario is very much in line with Comfort (2006) view that players need to feel as though the club chaplain is representing them as opposed to representing the club itself. This is something that being separate and distinct from the management structures of the club and team hierarchies facilitates. 
Addressing her fundamental belief that winning should not be to the detriment of player welfare, Grey-Thompson (2017) recommends that independent and confidential support is made available for athletes. By fulfilling this duty, chaplains enable elite youth footballers to discuss personal issues without harboring concerns regarding team selection, as expressed by Felicity Archer at Highfield FC:

Well, they can say anything can't they, so they can say if they're down, or they can say if they're whatever-they can tell him [the chaplain] anything because he's not going to make a decision on whether he's [the player] going to be on the pitch on Sunday or not.

As well as the pressure to be selected every week, elite youth footballers also face the prospect of potentially having their contract terminated and being released from their academy at the end of the season. Owen White at Sherburn United discussed the longer-term implications of players having access to an independent, confidential source within this context:

Someone who's not going to say to his coach "He can't play because he's got problems at home". Someone who's not going to stop him playing. Somebody who's not going to have influence on whether he stays in the academy or not. Somebody who's not going to think he's weak and perhaps ... y'know, make decisions on him as an individual that's in any way, shape or form, connected to his football. [This is] Vital ...

In terms of whether and to what extent chaplains should (continue to) be utilised in safeguarding provision, all respondents were extremely positive, providing several practical suggestions which included: being a consistent presence and an appropriate role model, and contributing towards positive mental wellbeing by encouraging players to speak up about their personal lives.

The demand for the continued input of chaplains was primarily driven by a need to increase resource and capacity around wider welfare support, with designated club staff often responsible for numerous players across multiple age groups. Unlike other organizational personnel, chaplains are able to focus their time and energy on the provision of pastoral support (Heskins 2006). In addition, given that the interests of academy staff are performance related their skill set is not geared towards pastoral and holistic support (Grey-Thompson 2017; Nesti 2010). An example of 'best practice' in response to these issues was provided by Sherburn United, who utilised a team of chaplains, with younger volunteers operating at academy level whilst the lead chaplain focused on senior players and club staff.

Another way in which such responsibilities might be devolved is through the intentional establishment of relationships between sports chaplains and other helping professionals. Indeed, recent research has suggested that there may well be a degree of overlap between the role of the sports chaplain and that of the sport psychologist, the former being viewed as someone who is primarily interested in the broader wellbeing of the individual, the latter as being primarily concerned with the enhancement of player performance (Nesti 2010). Gamble et al. (2013) observe that the sport psychologist and the sports chaplain bear similarities in their roles particularly concerning pastoral care, but that sports chaplains can also offer spiritual support which may facilitate discussion around specific faith issues as well as enhancing player contentment. Moreover, Nesti (2010) identifies an "overlap regarding issues of confidentiality and trust" (p. 109) across these roles to the extent that a cohesive working relationship between the two would appear sensible (Gamble et al. 2013). This is practically borne out by Hemmings and Chawner (2019) who provide a highly transparent account of the way in which such collaborative relationships might bear fruit. The findings presented here demonstrate that sports chaplains can indeed make a valuable contribution towards the safeguarding and wider welfare support of elite youth football players. In turn, greater intentionality by chaplains around the development of such relationships may well result in the provision of a more holistic support package for the athletes concerned. 


\section{Conclusions}

The aim of this paper has been to investigate the extent to which sports chaplains might contribute meaningfully towards the safeguarding and wider welfare support of elite youth athletes. In particular, the paper has provided an indication of the kinds of issues that young players might face within the context of English professional football and how other helping professionals negotiate and facilitate holistic welfare support.

Data findings reveal a number of welfare concerns including vulnerabilities surrounding the use of peer-group 'banter' which may be interpreted as bullying. It was acknowledged that safeguarding provision has developed significantly in recent years, particularly within football, and that young players are encouraged to talk about their concerns. However, an emerging theme was the reluctance of elite youth players to share personal issues with coaching staff due to a fear of jeopardising their futures. As a consequence of their independence from team management, sports chaplains are able to focus on the personal needs of players thereby fulfilling the recommendation of safeguarding campaigners to adopt a child-centred approach to elite sport development. This unique position of impartiality led respondents to endorse the potential of sports chaplains to contribute (or contribute further) towards the safeguarding and wider welfare support of elite youth footballers. Yet despite this acknowledgement, respondents made no specific reference to any formal or structured safeguarding provision with which club chaplains were involved, a trend which is also noted in the extant literature. Although this position may reflect the typically marginalized nature of the chaplain's role, it could also mirror the view expressed by two respondents that their initial perception of chaplaincy presumed evangelistic motives. That said, both respondents expressed a modified understanding of the chaplaincy role having witnessed their work. It could be argued that the strongest advocates of chaplaincy were those respondents who emanated from non-footballing backgrounds and who appeared to express a greater understanding and appreciation of holistic pastoral care. Conversely, respondents with coaching or playing experience within the professional game highlighted the strengths of the chaplaincy provision in relation to meeting educational standards and enhancing team performance. This observation indicates the need to increase awareness of the wider benefits of chaplaincy in terms of wider welfare support.

These findings have implications for policy and practice both within sports chaplaincy and elite youth football. Firstly, sports chaplains should be encouraged to provide specialized services to football academies in order that players and staff within these settings might benefit from their wider pastoral support. In turn, sports chaplaincy organisations should be encouraged to establish specific training events concerning safeguarding provision. It is also recommended that sports chaplains should better promote these services to host clubs and governing bodies in order to emphasise their potential contribution to safeguarding. In addition, further research should be carried out on the role of sports chaplains alongside existing welfare provision in order to assess their potential to make a more strategic contribution to holistic athlete support.

This study focused on elite youth football players however, corresponding research could explore the contribution of sports chaplains towards safeguarding provision in female or amateur/grassroots football and/or across other sports. Alternatively, future investigations might concentrate on the chaplain's potential to contribute to specific elements of safeguarding such as the influence of social media on young players thereby reducing risks to athlete welfare.

Author Contributions: Oliver 75\%, Parker 25\%.

Funding: This research received no external funding.

Conflicts of Interest: The authors declare no conflict of interest.

\section{References}

Baker, Joseph, Stephen Cobley, Jörg Schorer, and Nick Wattie. 2017. Routledge Handbook of Talent Identification and Development in Sport. London: Routledge. 
Baker, Math. 2006. You only sing when you're winning. In Footballing Lives: As Seen by Chaplains in the Beautiful Game. Edited by Jeffrey Heskins and Math Baker. Norwich: Canterbury Press, pp. 93-104.

Barker-Ruchti, Natalie, ed. 2019. Athlete Learning in Elite Sport: A Cultural Framework. London: Routledge.

BBC. 2018. Eighty Sports Coaches Convicted of Child Sex Abuse, Says Offside Trust. Available online: https: //www.bbc.com/sport/football/46453955 (accessed on 22 August 2019).

Boyers, John. 2016. Sports chaplaincy in the United Kingdom. In Sports Chaplaincy: Trends, Issues and Debates. Edited by Andrew Parker, Nick J. Watson and John B. White. London: Routledge, pp. 20-31.

Brackenridge, Celia, and Daniel Rhind. 2014. Child Protection in Sport: Reflections on Thirty Years of Science and Activism. Social Sciences, 326-40. [CrossRef]

Brackenridge, Celia, Darren Bishop, Sybille Moussali, and James Tapp. 2005. The Characteristics of Sexual Abuse in Sport: A Multi-dimensional Scaling Analysis of Events described in Media Reports. International Journal of Sport and Exercise Psychology 6: 395-406. [CrossRef]

Brackenridge, Celia, Joy D. Bringer, Claudi Cockburn, Gareth Nutt, Andy Pitchford, Kate Russell, and Zofia Pawlaczek. 2004. The Football Association's Child Protection Research Project 2002-2006: Rationale, Design and First Year Results. Managing Leisure 9: 30-46. [CrossRef]

Bryman, Alan. 2015. Social Research Methods, 5th ed. London: Oxford.

Caperon, John, Andrew Todd, and James Walters, eds. 2018. A Christian Theology of Chaplaincy. London: Kingsley.

Charmaz, Kathy. 2000. Grounded theory: Objectivist and constructivist methods. In Handbook of Qualitative Research, 2nd ed. Edited by N. Denzin and Y. Lincoln. Thousand Oaks: Sage, pp. 509-35.

Charmaz, Kathy. 2014. Constructing Grounded Theory, 2nd ed. London: Sage.

Comfort, Alan. 2006. Shall we sing a song for you. In Footballing Lives: As Seen by Chaplains in the Beautiful Game. Edited by Jeffrey Heskins and Math Baker. Norwich: Canterbury Press, pp. 39-49.

Conn, David. 2018. Aston Villa Remove Kevin MacDonald from Coaching after New Bullying Claims. The Guardian . December 13. Available online: https:/www.theguardian.com/football/2018/dec/13/aston-villa-removekevin-macdonald-coaching-new-bullying-claims-gareth-farrelly (accessed on 22 August 2019).

Gamble, Richard, Denise Hill, and Andrew Parker. 2013. Revs and Psychos': Role, Impact and Interaction of Sport Chaplains and Sport Psychologists within English Premiership Soccer. The Sport Psychologist 25: 249-64. [CrossRef]

Grey-Thompson, Tanni. 2017. Duty of Care in Sport, Independent Report to Government. Available online: http:// www.sportsthinktank.com/uploads/final-copy---duty-of-care-report-2018.pdf (accessed on 22 August 2019).

Giulianotti, Richard, Fred Coalter, Holly Collison, and Simon Darnell. 2019. Rethinking Sportland: A New Research Agenda for the Sport for Development and Peace Sector. Journal of Sport and Social Issues. [CrossRef]

Hemmings, Brian, Nick J. Watson, and Andrew Parker. 2019. Sport, Psychology and Christianity: Welfare, Performance and Consultancy. London: Routledge.

Hemmings, Brian, Nick J. Watson, Andrew Parker, Damien Clement, Monna Arrivinen-Barrow, and Mark Oliver. 2019. Introduction. In Sport, Psychology and Christianity: Welfare, Performance and Consultancy. Edited by Brian Hemmings, Nick J. Watson and Andrew Parker. London: Routledge, pp. 1-9.

Hemmings, Brian, and David Chawner. 2019. The sport psychologist and the club chaplain supporting welfare: Reflections on five years of collaboration in English professional cricket. In Sport, Psychology and Christianity: Welfare, Performance and Consultancy. Edited by Brian Hemmings, Nick J. Watson and Andrew Parker. London: Routledge, pp. 42-53.

Heskins, Jeffrey. 2006. Who are you, who are you? In Footballing Lives: As Seen by Chaplains in the Beautiful Game. Edited by Jeffrey Heskins and Math Baker. Norwich: Canterbury Press, pp. 1-13.

Heskins, Jeffrey, and Math Baker, eds. 2006. Footballing Lives: As Seen by Chaplains in the Beautiful Game. Norwich: Canterbury Press.

International Centre of Ethics in Sport. 2016. Safeguarding Youth Sport. Available online: http://ec.europa.eu/ assets/eac/sport/forum/docs/2ii1-pa2013-sys.pdf (accessed on 22 August 2019).

Kavanagh, Emma J. 2014. The Dark Side of Sport: Athlete Narratives of Maltreatment in High Performance Environments. Bournemouth: Bournemouth University.

Knight, Roger. 2006. You don't know what you're doing. In Footballing Lives: As Seen by Chaplains in the Beautiful Game. Edited by Jeffrey Heskins and Math Baker. Norwich: Canterbury Press, pp. 68-79.

Manley, Andrew, Martin Roderick, and Andrew Parker. 2016. Disciplinary mechanisms and the discourse of identity: The creation of 'silence' in an elite sports academy. Culture and Organization 22: 221-44. [CrossRef] 
Mason, Phil. 2006. By far the greatest team. In Footballing Lives: As Seen by Chaplains in the Beautiful Game. Edited by Jeffrey Heskins and Math Baker. Norwich: Canterbury Press, pp. 39-49.

Morris, Steven. 2019. Football Coach Bob Higgins Guilty of 45 Counts of Indecent Assault. The Guardian. May 23. Available online: https:/www.theguardian.com/uk-news/2019/may/23/football-coach-bob-higgins-guilty-of45-counts-of-indecent-assault (accessed on 22 August 2019).

Mountjoy, Margo, Daniel Rhind, Anne Tiivas, and Michele Leglise. 2015. Safeguarding the child athlete in sport: A review, a framework and recommendations for the IOC youth athlete development model. British Journal of Sports Medicine 49: 883-86. [CrossRef] [PubMed]

National Society for the Prevention of Cruelty to Children. 2016. Available online: https://www.nspcc.org.uk/ preventing-abuse/safeguarding/ (accessed on 22 August 2019).

Nesti, Mark. 2010. Psychology in Football: Working with Elite and Professional Players. London: Routledge.

Nesti, Mark, and Chris Sulley. 2015. Youth Development in Football. Lessons from the World's Best Academies. London: Routledge.

Ong, Chin Wei, Philippa McGregor, and Cherrie Daley. 2018. The Boy Behind the Bravado: Player advanced safety and support in a professional football academy setting. Sport and Exercise Psychology Review 14: 1-30.

Parker, Andrew, and Andrew Manley. 2016. Identity. In Studying Football. Edited by Ellis E. Cashmore and Kevin Dixon. London: Routledge, pp. 97-112.

Parker, Andrew, and Andrew Manley. 2017. Goffman, Identity and Organisational Control: Elite Sports Academies and Social Theory. Sociology of Sport Journal 34: 211-22. [CrossRef]

Parker, Andrew. 1995. Great Expectations: Grimness or Glamour? The Football Apprentice in the 1990s. The Sports Historian 15: 107-28. [CrossRef]

Parker, Andrew. 2001. Soccer, Servitude and Sub-Cultural Identity: Football Traineeship and Masculine Construction. Soccer and Society 2: 59-80. [CrossRef]

Parker, Andrew. 2006. Lifelong Leaning' to Labour: Apprenticeship, Masculinity and Communities of Practice. British Educational Research Journal 35: 687-701. [CrossRef]

Parker, Andrew. 2016. Staying Onside on the Inside; Men, masculinities and the research process. In Gender Identity and Research Relationships. Edited by Michael R. M. Ward. Studies in Qualitative Methodology. London: Emerald Group Publishing Limited, vol. 14, pp. 105-22.

Parker, Andrew, Nick J. Watson, and John B. White, eds. 2016. Sports Chaplaincy: Trends, Issues and Debates. London: Routledge.

Pattison, Steven. 2015. Situating Chaplaincy in the United Kingdom: The acceptable Face of 'Religion'? In $A$ Handbook of Chaplaincy Studies: Understanding Spiritual Care in Public Places. Edited by Christopher Swift, Mark Cobb and Andrew Pattinson. London: Ashgate, pp. 13-30.

Pitchford, Andy, Celia Brackenridge, Joy D. Bringer, Claudi Cockburn, Gareth Nutt, Zofia Pawlaczek, and Kate Russell. 2004. Children in Football: Seen but not Heard. Soccer in Society 5: 43-60. [CrossRef]

Professional Footballers' Association. 2017. PFA Youth Advisory Booklet 2017-18. Available online: https: //www.thepfa.com/-/media/Files/PFA-Youth-Advisory-Booklet-2017-2018.pdf (accessed on 22 August 2019).

Roan, Dan. 2019. Manchester City Launch Child Sexual Abuse Victim Payment Scheme. Available online: https://www.bbc.com/sport/football/47532719 (accessed on 22 August 2019).

Roderick, Martin. 2006. The Work of Professional Football: A labour of Love? London: Routledge.

Roe, Christopher, and Andrew Parker. 2016. Sport, Chaplaincy and Holistic Support (The Elite Player Performance Plan (EPPP) in English Professional Football. Practical Theology 9: 169-82. [CrossRef]

Slater, Victoria. 2015. Chaplaincy Ministry and the Mission of the Church. London: SCM Press.

Sport England. 2016. Towards an Active Nation-Strategy 2016-2021. Available online: https://www.sportengland. org/media/10629/sport-england-towards-an-active-nation.pdf (accessed on 22 August 2019).

Sport Safeguarding Partnership. 2016. Strategic Plan. Available online: https://hecpsu.org.uk/resource-library/ 2017/sport-safeguarding-partnership-2016-2021-strategic-plan/ (accessed on 22August 2019).

Strauss, Anslem, and Juliet Corbin. 1998. Basics of Qualitative Research: Techniques and Procedures for Developing Grounded Theory. Thousand Oaks, CA: Sage Publications, Inc.

Swift, Christopher, Mark Cobb, and Andrew Pattinson, eds. 2015. A Handbook of Chaplaincy Studies: Understanding Spiritual Care in Public Places. London: Ashgate. 
Taylor, Daniel. 2018. Barry Bennell: The predatory Pied Piper who made stars and shattered lives. The Guardian. February 15. Available online: https:/www.theguardian.com/football/2018/feb/15/barry-bennell-abusemanchester-city-crewe (accessed on 22 August 2019).

The English Football League. 2018. Charter for Academy Players and Parents. Available online: https://www.efl. com/siteassets/efl-documents/charter-for-academy-players-and-parents-2017-18-e-book-1.pdf (accessed on 22 August 2019).

The Football Association. 2015. Grassroots Football Safeguarding Children. London: The Football Association.

The Football Association. 2017. Keeping Football Safe and Enjoyable-English Football's Ongoing Work to Protect Young People Who Play or Participate in Our National Sport. Available online: http://www.thefa.com/-/ media/cfa/global/files/safeguarding/keeping-football-safe-enjoyable.ashx (accessed on 22 August 2019).

The Premier League. 2018. Elite Player Performance Plan. Available online: https:/www.premierleague.com/ youth/EPPP (accessed on 22 August 2019).

Wallace, S. 2019. Peter Beardsley Leaves Newcastle United Following Bullying Allegations. Daily Telegraph. March 6. Available online: https://www.telegraph.co.uk/football/2019/03/06/peter-beardsley-leavesnewcastle-unitedfollowingbullying-allegations/ (accessed on 22 August 2019).

Weir, Stuart. 2016. Sports chaplaincy, a global overview. In Sports Chaplaincy: Trends, Issues and Debates. Edited by Andrew Parker, Nick J. Watson and John B. White. London: Routledge, pp. 9-19.

(C) 2019 by the authors. Licensee MDPI, Basel, Switzerland. This article is an open access article distributed under the terms and conditions of the Creative Commons Attribution (CC BY) license (http://creativecommons.org/licenses/by/4.0/). 